\title{
Intangible Capital: Culture of Innovation and its Impact on the Cash Flow Multiple
}

By

James R. Gregory, University of South Florida

1 culture of innovation is a desirable attribute to be associated with any company. Such an attribute helps to position the company in the mind of the consumer, whether that person is purchasing a product or acquiring shares of stock ownership in the company. Apple Inc. comes to mind as an example of a company that has nurtured their image to create a culture of innovation that applies to both its corporate and product brands. The financial result is that both Apple's products and stock sell for a premium price over what would be expected of a generically branded company with the same product line. That pre-

mium effect is described as intangible capital.

In this research, culture of innovation (COI) is defined as the perception of a company that prioritizes the advancement of new ideas that create value across all operations. The word perception in this context is important because it is the views held by an audience of engaged but impartial observers of companies. The quantitative perceptions held by these impartial observers may not be the actual innovation that exists in these companies. However, the perceptions, when aggregated across many interviews, offer a consistent snapshot of companies from the public perspective. When examined longitudinally, they become a reliable tool for evaluating the effectiveness of business strategy and the resulting financial impact on an outcome measure known as the cash flow multiple (CFM). The cash flow multiple is a company-wide calculation of financial performance, which is the measure that examines the premium that can potentially be achieved by improving operations or perceptions of the company. The CFM is determined by dividing the stock price per share by the cash flow per share, which provides a calculation that reflects the value of both the cash flow and market capitalization. The CFM also has the advantage of being able to project expected returns into the future, which will help a company to evaluate the re turn on investment (ROI) over the continuum of

time.

This study utilizes the CoreBrand Index ${ }^{\circledR}$ (CBI), which is a quantitative research survey that examines intangible attributes of 800 companies and fielded consistently every year since 1990. In 2016, the survey tested a new intangible attribute culture of innovation added to the study amongst a subset of 160 companies. The primary purpose of this new research was to examine the role that a culture of innovation plays in predicting whether a firm might have a higher or lower cash flow multiple. This research is a potentially new gateway by which all intangible assets can be measured, valued, and managed, which is ultimately leading to a theory of intangible capital.

Keywords: Intangible assets, fair value, brand equity, corporate brands, accountability, intangible cap ital, innovation, cash flow, CoreBrand Index, valuation, capital, FASB

Copyright ( ) 2018, James R. Gregory. This article is published under a Creative Commons BY-NC license. Permission is granted to copy and distribute this article for non-commercial purposes, in both printed and electronic formats 
CBI quantitative research measures the impartial observer's familiarity with corporate brands and favorability toward specific attributes of corporations to devise brand power ratings. The CBI measures have been historically utilized to identify the strength of the corporate brand and ultimately its financial impact on the company. For the dissertation research, the author verified the role of each of the existing attributes in influencing market capitalization. Specifically, the effects of three historical attributes of the company (a) overall reputation, (b) perceptions of management, and (c) investment potential were examined for their impact on the cash flow multiple. The predictive impact of a new CBI attribute, (d) culture of innovation on the dependent variable cash flow multiple, was subsequently examined. Finally, the effect of the combined attributes on market capitalization was examined as identified by the result of the cash flow multiple as the dependent variable.

\section{Research Questions}

Q1. What are the effects of (a) overall reputation, (b) perceptions of management, and (c) investment potential on the cash flow multiple (verification and replication of prior research)?

Q2. What are the effects of (d) culture of innovation on the cash flow multiple?

Connecting the cash flow multiple to market value allows for apples-to-apples comparisons between different sized companies and identifies the premium that an investor pays for a specific stock given its level of cash flow. CFM is the dependent variable throughout the study. It is a better measurement instrument than, for example, PE ratio, because cash flow is often more indicative of business performance while earnings can frequently be negative based on accounting adjustments. The study was conducted employing chi-squared automatic interaction detector (CHAID), which utilizes Pearson's Chi-square tests of independence to examine relationships between categorical variables building non-binary decision trees. CHAID is a useful tool for examining a large amount of data when sorting through multiple potential answers.

\section{Findings}

The research findings reaffirmed empirical knowledge about the historical attributes of the CoreBrand Index and their relative predictive strengths and introduced a robust new predictor. Specifically, the study found that:
- Overall reputation was a strong longterm predictor of a company's CFM.

- Investment potential was an important short-term predictor of CFM.

- Perception of management was a weaker but still positive predictor of CFM.

- Culture of innovation was now found to be the strongest predictor of CFM.

- Favorability added culture of innovation improved predictability of the CFM.

Each of the attributes CoreBrand tracks and contributes to the corporate brand and the CFM. The historical attributes when combined are known as favorability (without culture of innovation) and correctly predicts the CFM $64 \%$ of the time. When the culture of innovation attribute was combined with favorability (enhanced favorability) the predictive power increased significantly from $64 \%$ to $77 \%$.

\section{Conclusions}

There is overwhelming evidence of the significant and growing value of intangible assets when a company is sold, but the value is unaccounted for and unreported when the company is running at pace. This is because accounting standards do not report the financial value of internally-grown intangible assets. This creates a dilemma for investors who want to understand if leadership is properly managing these assets and generating a return on the investments spent on them. It also creates a management dilemma for executives who want to build the total value of the enterprise but fear the financing of projects for which the returns cannot be reported on financial statements.

CoreBrand Index research offers a robust methodology and the target audience of impartial observers has provided consistent decades long longitudinal quantitative research, which removes the subjective bias that often muddies other valuation models. The research method helps to remove the vertical industry and audience bias by creating a horizontal examination, which measures the perceptions of the impartial observers across industries. It also helps to explain how perceptions and drivers of the corporate brand changed depending on economic, industry, societal, and company conditions.

The need for a solution for measuring, valuing, and managing intangible assets is overwhelming. With intangible assets growing exponentially as a component of enterprise value, it is unproductive to allow 
them to go unmanaged. The alternative to moving forward is for intangible assets to remain unmanaged and unaccounted for except at the time the company is sold. Intangible capital is a conceptual framework proven over time that can help senior executives to better measure, value, and manage their intangible assets.

Note: CoreBrand Index ${ }^{\oplus}$ is a registered trademark of Tenet Partners.

\section{Where to Find Out More}

The author welcomes questions or inquiries. For more information please contact James Gregory.

jgregory@tenetpartners.com

James.Gregory@Conference-Board.org

Review
This article was accepted under the editorial re-
view option. For futher details, see the descrip-
tions at:
http://mumabusinessreview.org/peer-review-op-
tions/

\section{Author}

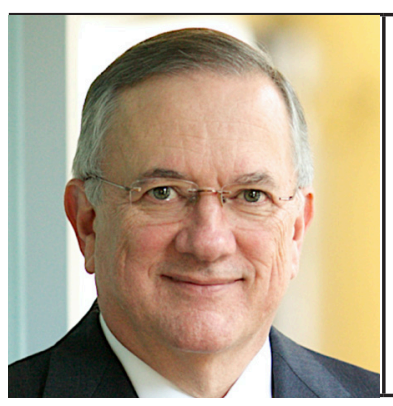

Dr. James R. Gregory is a leading expert on measuring the strength of corporate brands and the resulting impact on financial performance. He currently serves as a senior fellow of The Conference Board. Also, Jim is the chairman of Tenet Partners, a global brand strategy and innovation firm based in New York City. Jim also serves on the Board of Trustees of the Virginia Commonwealth University Foundation. He has written five books on corporate branding and is a noted speaker on the subject. He is currently working on a new book that will be published late in 2019 The Theory of Intangible Capital. 